\title{
Pengaruh Gaya Kepemimpinan dalam memoderasi hubungan Disiplin dan Kepuasan Kerja terhadap Kinerja Karyawan Unit Pelaksana Teknis Daerah (UPTD) Balai Kesehatan dan Olahraga Masyarakat dan Pelatihan Kesehatan (BKOM DAN PELKES) Provinsi Sumatera Barat
}

\author{
Oleh \\ Ertati Murni \\ Program Studi Magister Manajemen, Program Pascasarjana STIE”KBP” Padang \\ ertati_murni@yahoo.com
}

\begin{abstract}
This study aims to examine and analyze the influence of leadership style, work discipline, and job satisfaction on employee performance UPTD BKOM and Pelkes. Provinsi Sumatera Barat. The results of the analysis proved that the influence of test and analyze the influence of leadership style, work discipline, and job satisfaction simultaneously on the performance of employees in contributions leadership style, work discipline, and job satisfaction on the performance of employees amounted to $57.6 \%$.

In the first hypothesis test obtained the hypothesis accepted, meaning that partially contained positive and significant effect of leadership style on employee performance. To test the second hypothesis obtained the hypothesis accepted, meaning that there are significant partial positive and significant correlation between the performance of employees work discipline.

For testing the third hypothesis obtained the hypothesis accepted, meaning that there are significant partial positive and significant correlation between job satisfaction on employees' performance. And the value of the F test in the concluded that leadership style, work discipline, and satisfaction karja together have a significant and positive impact on the performance of which the employees' job satisfaction is very strong the effect of the variable of leadership style and work discipline. Suggested can be done by the agency and the management needs to pay attention to the division of labor in accordance with the ability of employees by level of education which is owned by employees.
\end{abstract}

Keywords: leadership style, work discipline, and job satisfaction on performance

\section{A. PENDAHULUAN}

Kinerja pegawai tidak lepas dari peran pemimpinnya. menurut Bass(1990), peran kepemimpinan atasan dalam memberikan kontribusi padakaryawan untuk pencapaian kinerja yang optimal dilakukan melalui lima cara,yaitu : (1) pemimpin mengklarifikasi apa yang diharapkan dari karyawannya,secara khusus tujuan dan sasaran dari kinerja mereka, (2) pemimpin menjelaskan bagaimana memenuhi harapan tersebut, (3) pemimpin mengemukakan kriteria dalam melakukan evaluasi dari kinerja secara efektif, (4) pemimpin memberikan umpan balik ketika karyawan telah mencapai sasaran, dan (5) pemimpin mengalokasikan imbalan berdasarkan hasil yang telah mereka capai. Kepemimpinan adalah kemampuan untuk mempengaruhi 
orang lain untuk mencapai tujuan dengan antusias (David, Keith, 1985). Seorang pemimpin harusmampu mempengaruhi para bawahannya untuk bertindak sesuai dengan visi, misidan tujuan perusahaan. Pemimpin harus mampu memberikan wawasan, membangkitkan kebanggaan, serta menumbuhkan sikap hormat dan kepercayaan dari bawahannya.

Kinerja organisasi secara keseluruhan, sangat tergantung pada pemimpin organisasi tersebut, baik organisasi yang berorientasi bisnis maupun yang berorientasi public. Kualitas dari seorang pemimpin merupakan faktor terpenting dalam keberhasilan dan kegagalan organisasi (Bass,1990, dalam Menon, 2002). Kualitas kepemimpinan ini ditentukan oleh sejauh mana pemimpin mampu mengambil resiko, menginspirasi bawahannya, dan menciptakan peluang demi tercapainya kesuksesan organisasi. Begitu besarnya peranan pemimpin sehingga Schein (19932), Nahavandi \& Malekzadeh menyatakan pemimpin mempunyai pengaruh yang sangat besar terhadap keberhasilan organisasi.

Disiplin organisasi menjadi perhatian penting dalam banyak penelitiankarena memberikan dampak signifikan terhadap perilaku kerja seperti kinerja,kepuasan kerja, absensi karyawan dan juga turn over karyawan. Disiplin dalam organisasi akan membuat pekerja memberikan yang terbaik kepada organisasitempat dia bekerja. Van Scooter (2000) menyatakan bahwa pekerja dengan disiplin yang tinggi akan lebih berorientasi pada kerja. Disebutkan pula bahwapekerja yang memiliki disiplin organisasi tinggi akan cenderung senang membantu dan dapat bekerja sama.

Kepuasan kerja pada dasarnya adalah tentang apa yang membuat seseorang bahagia dalam pekerjaannya atau keluar dari pekerjaanya. Faktor-faktor yang mempengaruhi kepuasan kerja pegawai secara signifikan adalah faktor-faktor yang berhubungan dengan pekerjaan itu sendiri, dengan kondisi kerja, dengan pimpinan, dengan rekan kerja, dengan pengawasan, dengan promosi jabatan dan dengan gaji. Pinder (1984) menyatakan bahwa salah satu faktor yang menyebabkan ketidakpuasan kerja ialah sifat penyelia yang tidak mau mendengar keluhan dan pandangan pekerja dan mau membantu apabila diperlukan. Blakely (1993) membuktikan bahwa pekerja yang menerima penghargaan dari penyelia yanglebih tinggi dibandingkan dengan penilaian mereka sendiri akan lebih puas.

Gaya kepemimpinan, disiplin kerja dan kepuasan karyawan merupakan salah satu elemen penting dalam menentukan keberhasilan kinerja seseorang. data Tingkat Disiplin Pegawai pada BKOM dan PELKES Provinsi Sumatera Barat yang dilihat dari tingkat kehadiran pegawai sebagai berikut :

Tabel 1.

Data Tingkat Kehadiran Pegawai BKOM dan Pelkes Provinsi Sumatera Barat Tahun 2014

\begin{tabular}{|c|l|c|c|c|}
\hline No & \multicolumn{1}{|c|}{ Bulan } & $\begin{array}{c}\text { Jumlah } \\
\text { Kehadiran }\end{array}$ & $\begin{array}{c}\text { Jumlah } \\
\text { Ketidakhadiran }\end{array}$ & $\begin{array}{c}\text { Persentase } \\
\text { ketidakhadiran }\end{array}$ \\
\hline 1 & Januari & 45 & 6 & 12,11 \\
\hline 2 & Februari & 46 & 5 & 10,05 \\
\hline 3 & Maret & 47 & 4 & 7,84 \\
\hline 4 & April & 45 & 6 & 12,11 \\
\hline 5 & Mei & 47 & 4 & 7,84 \\
\hline 6 & Juni & 50 & 1 & 2 \\
\hline 7 & Juli & 45 & 6 & 12,11 \\
\hline 8 & Agustus & 45 & 6 & 12,11 \\
\hline 9 & September & 46 & 5 & 10,05 \\
\hline
\end{tabular}




\begin{tabular}{|c|l|c|c|c|}
\hline 10 & Oktober & 45 & 6 & 12,11 \\
\hline 11 & November & 47 & 4 & 7,84 \\
\hline 12 & Desember & 45 & 6 & 12,11 \\
\hline & Rata-rata & 46,08 & 4,92 & 9,86 \\
\hline
\end{tabular}

Sumber data: BKOM dan Pelkes, 2015

Dari data diatas dapat dilihat bahwa tingkat ketidakhadiran pegawai pada BKOM dan Pelkes Provinsi Sumatera Barat cukup tinggi yang 9, $86 \%$, hal ini menunjukkan kedisiplinan pegawai masih rendah, hal ini tentu akan berpengaruh terhadap kinerja BKOM dan Pelkes Provinsi Sumatera Barat baik secara langsung maupun tidak langsung. Hal ini dapat dilihat dari realisasi dana yang digunakan pada BKOM dan Pelkes Provinsi Sumatera Barat selama 4 tahun terakhir sebagai berikut;

Tabel 2

Data Realisasi Dana APBD, APBN, Pusat dan PNPB UPTD BKOM dan Pelkes Provinsi Sumatera Barat

\begin{tabular}{|c|c|c|c|c|c|c|c|c|c|}
\hline No & Sumber & \multicolumn{8}{|c|}{ Penyerapan Dana (\%) } \\
\cline { 3 - 11 } & Dana & $\begin{array}{c}2011 \\
\text { (Juta) }\end{array}$ & $\%$ & $\begin{array}{c}2012 \\
\text { (juta) }\end{array}$ & $\%$ & $\begin{array}{c}2013 \\
\text { (juta) }\end{array}$ & $\%$ & $\begin{array}{c}2014 \\
\text { (juta) }\end{array}$ & $\%$ \\
\hline 1 & APBD & 866,81 & 88,87 & 982,55 & 92,83 & $1.287,9$ & 90,03 & $1.578,3$ & 95,09 \\
\hline 2 & APBN & 832,59 & 91,58 & 420,85 & 92,18 & 308,73 & 92,15 & 50,73 & 93,68 \\
\hline 3 & PUSAT & $1.575,8$ & 95,45 & 369,1 & 96,60 & 966.64 & 96,6 & 983,72 & 88,19 \\
\hline 4 & PNBP & 387,1 & 146 & 438,98 & 163,4 & 421,2 & 145,2 & 404,46 & 139,5 \\
\hline
\end{tabular}

Sumber: LAKIP UPTD BKOM dan Pelkes Provinsi Sumatera Barat, 2015

Dari tabel.2. tersebut dapat terlihat bahwa penyerapan dana yang bersumber dari pusat, APBD dan APBN masih rendah dan belum bisa mencapai angka $100 \%$ seperti penyerapan dana PNBP.

Dengan semakin majunya perkembangan dunia, maka kebutuhan akan peningkatan kinerja sangat penting artinya bagi organisasi. Untuk mendapatkan kepercayaan masyarakat secaraterus-menerus akan suatu produk tidaklah mudah, maka dariUPTD BKOM dan PELKES Provinsi Sumatera Barat selalu berupaya meningkatkan kualitas pelayanannya,menjaga kelancaran pendidikan dan pelatihan serta selalu mengedepankan pelayanan yang bagus. Untuk itu UPTD BKOM DAN PELKES PROV. SUMATERA BARAT selalu berusaha menciptakan pelayanan bermutu untuk memenuhi sarana pelatihan serta memberikan pelayanan terbaik melalui pelatihan yang berkualitas.

Mengingat pentingnya masalah tersebut, maka tujuan penelitian ini adalah untuk meneliti 1) Pengaruh disiplin kerja terhadap kinerja karyawan UPTD BKOM dan PELKES Provinsi Sumatera Barat.2) Pengaruh gaya kepemimpinan dalam memoderasi hubungan disiplin kerja dengan kinerja karyawan UPTD BKOM dan PELKES Provinsi Sumatera Barat.3) Pengaruh kepuasan kerja terhadap kinerja karyawan UPTD BKOM dan PELKES Provinsi Sumatera Barat.4) Pengaruh gaya kepemimpinan dalam memoderasi hubungan disiplin kerja dan kepuasan kerja terhadap kinerja Karyawan UPTD BKOM dan PELKES Provinsi Sumatera Barat. 5) Pengaruh gaya kepemimpinan dalam memoderasi hubungan kepuasan kerja terhadap kinerja karyawan UPTD BKOM dan PELKES Provinsi Sumatera Barat. 


\section{B. KAJIAN TEORI}

Menurut Mangkunegara (2000: 67), kinerja atau prestasi kerja adalah hasilkerja kualitas dan kuantitas yang dicapai oleh seorang pegawai dalam melaksanakantugasnya sesuai dengan tanggung jawab yang diberikan kepadanya. Sedangkanmenurut Gibson et al. (1996:95) kinerja karyawan merupakan suatu ukuran yangdapat digunakan untuk menetapkan perbandingan hasil pelaksanaan tugas, tanggungjawab yang diberikan oleh organisasi pada periode tertentu dan relatif dapat digunakan untuk mengukur prestasi kerja atau kinerja organisasi.

Menurut Rivai (2005:14), kata kinerja merupakan terjemahan dari kata performance yang berasal dari kata to perform dengan beberapa entries yaitu $: 1$. Melakukan, menjalankan, melaksanakan (to do or carry out, execute)2. Memenuhi atau melaksanakan kewajiban suatu niat atau nazar (to dischargeof fulfil; as vow)3. Melaksanakan atau menyempurnakan tanggung jawab (to execute orcomplete an understanding)4. Melakukan sesuatu yang diharapkan oleh orang atau mesin (to do what isexpected of a person machine).Irawan (2000 :17) menyatakan bahwa kinerja adalah terjemahan dari kataperformance. Pengertian kinerja atau performance sebagai output seorang pekerja,sebuah output proses manajemen, atau suatu organisasi secara keseluruhan, dimana output tersebut harus dapat ditunjukkan buktinya secara konkret dan dapat diukur(dibandingkan dengan standar yang telah ditentukan).

Kepemimpinan memegang peranan yang sangat penting dalam manajemen organisasi. Kepemimpinan dibutuhkan manusia karena adanya keterbatasanketerbatasan tertentu pada iri manusia. Dari sinilah timbul kebutuhan untuk memimpin dan dipimpin. Gaya kepemimpinan pada dasarnya mengandung pengertian sebagai suatuperwujudan tingkah laku dari seorang pemimpin yang menyangkut kemampuannyadalam memimpin. Menurut Tjiptono(2001:161), gaya kepemimpinan adalah suatu cara yang digunakan pemimpin dalam berinteraksi dengan bawahannya. Pendapat lain menyebutkan bahwa gaya kepemimpinan adalah pola tingkah laku (kata-kata dan tindakan-tindakan) dari seorang pemimpin yang dirasakan oleh orang lain (Hersey, 2004:29).

Menurut Heidjrachman dan Husnan (2002:173) seorang pemimpin harus memiliki sifat perceptive artinya mampu mengamati dan menemukan kenyataan darisuatu lingkungan. Untuk itu ia harus mampu melihat, mengamati, dan memahami keadaan atau situasi tempat kerjanya, dalam artian bagaimana para bawahannya,bagaimana keadaan organisasinya, bagaimana situasi penugasannya, dan jugat entang kemampuan dirinya sendiri. la harus mampu menyesuaikan diri dengan lingkungannya. Maka dari itu dalam memilih gaya kepemimpinan yang akan digunakan, perlu dipertimbangkan berbagai faktor yang mempengaruhinya.

Disiplin Kerja menurut Siswanto (2002). dapat didefinisikan sebagai "suatu sikap menghormati, menghargai, patuh dan taat terhadap peraturan-peraturan yang berlaku, baik yang tertulis maupun tidak tertulis serta sanggup menjalankannya dan tidak mengelak untuk menerima sanksi-sanksinya apabila ia melanggar tugas dan wewenang yang diberikan kepadanya”. Kemudian Nitisemito (2000) menyatakan bahwa disiplin kerja adalah suatu sikap, tingkah laku dan perbuatan yang sesuai dengan peraturan baik yang tertulis maupun tidak tertulis. Menurut Syadam (2006) disiplin kerja merupakan setiap kesediaan dan kerelaan seseorang untuk menaati dan mematuhi segala peraturan dan norma-norma yang berlaku disekitarnya. Berdasarkan pendapat di atas dapat disimpulkan bahwa disiplin kerja adalah kesediaan dan kerelaan seseorang untuk mematuhi dan mentaati aturan-aturan dannorma-norma berlaku baik secara fakta maupun tidak tertulis dalam melaksanakan tugasnya. 
Kepuasan kerja adalah suasana psikologis tentang perasaan menyenangkan atau tidak menyenangkan terhadap pekerjaan mereka (Davis, Keith, 1985). Sementara itu Porter dan Lawler dalam Bavendam, J. (2000) menjelaskan bahwa kepuasan kerja merupakan bangunan unidimensional, dimana seseorang memiliki kepuasan umum atau ketidakpuasan dengan pekerjaannya. Vroom sebagaimana dikutip oleh Ahmad, M.A. Roshidi (1999) mendefinisikan kepuasan kerja sebagai satu acuan dari orientasi yang efektif seseorang pegawai terhadap peranan mereka pada jabatan yang dipegangnya saat ini. Sikap yang positif terhadap pekerjaan secara

konsepsi dapat dinyatakan sebagai kepuasan kerja dan sikap negatif terhadap pekerjaan sama dengan ketidakpuasan. Definisi ini telah mendapat dukungan dari Smith dan Kendall (1963) yang menjelaskan bahwa kepuasan kerja sebagai perasaan seseorang pegawai mengenai pekerjaannya. Secara sederhana, job satisfaction dapat diartikan sebagai apa yang membuat orang-orang menginginkan dan menyenangi pekerjaan. Sedangkan Edison (2002) menyebutkan sumber kepuasan kerja terdiri atas pekerjaan yang menantang, imbalan yang sesuai, kondisi/ lingkungan kerja yang mendukung, dan rekan kerja yang mendukung. Indra, Hary dalam penelitiannyamenyebutkan bahwa faktor yang mempengaruhi kepuasan kerja pegawai secarasignifikan adalah : faktor yang berhubungan dengan pekerjaan, dengan kondisi kerja, dengan teman sekerja, dengan pengawasan, dengan promosi jabatan dan dengan gaji.

\section{Kerangka Konseptual}

Bentuk hubungan variabel yang akan dibahas pada penelitian ini adalah variabel terikat yaitu Kinerja (Y), dan variabel bebas yaitu Disiplin Kerja paramedic $\left(\mathrm{X}_{1}\right)$ dan Kepuasan Kerja $\left(\mathrm{X}_{2}\right)$ serta gaya Kepemimpinan $(\mathrm{M})$ sebagai variable pemoderasi, maka bentuk hubungan variabelnya adalah sebagai berikut:

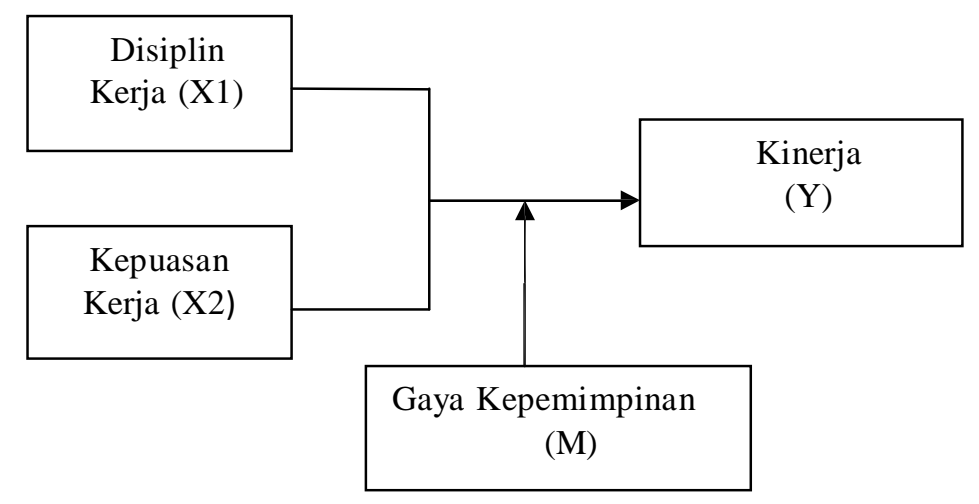

\section{METODE PENELITIAN}

Populasi adalah kelompok elemen yang lengkap, biasanya berupa orang, objek atau peristiwa dimana kita tertarik untuk mempelajarinya atau menjadi objek penelitian (Kuncoro, 2003). Menurut Sekaran (2003), populasi merupakan sekelompok orang, peristiwa atau sesuatu yang menarik perhatian penelitian untuk diteliti.

Untuk menentukan sampel digunakan metode sensus dimana menjadi populasi dalam penelitian ini adalah seluruh Pegawai Negeri Sipil yang bertugas pada Balai Kesehatan Olahraga Masyarakat dan Pelatihan Kesehatan Provinsi Sumatera Barat dengan jumlah pegawai 50 orang. 
Teknik Pengumpulan Data dilakukan dengan cara daftar pertanyaan atau menggunakan questionnaire. Dalam hal ini menggunakan kuesioner dengan skala Likert, sedangkan data skunder diperoleh pasien rawat Inap di rumah sakit Bhayangkara Kota Padang. Sedangkan teknik Analisis Data digunakan adalah analisis deskriptif, uji validitas dan reliabilitas, uji asumsi klasik, dan analisis regresi linear berganda dan Moderated Regression Analysis.

\section{Operasionalisasi Variabel}

Kinerja adalah unjuk kerja pegawai baik dari segi kualitas maupun kuantitas yang dicapai oleh seseorang pegawai dalam melaksanakan tugasnya sesuai dengan tanggung jawab yang diberikan kepadanya dengan enam butir pernyataan (Dyne dan Graham (1994) dalam Fuad Mas'ud (2004 : 206).

Kepuasan kerja adalah cara pegawai merasakan dirinya atau pekerjaannya. Dengan lima butir pernyataan (Hartline, Michael D. dan O.C. Ferrel (1996) dalam Fuad Mas'ud (2004 : 188). Gaya kepemimpinan adalah suatu pola perilaku yang dirancang untuk memadukan kepentingan - kepentingan organisasi dan personalia guna mengejar beberapa sasaran dengan enam butir pernyataan (Yeh Quey-Jen (1996) dalam Fuad Mas'ud (2004 : 385). Sedangkan Disiplin Kerja yang dalam penelitian ini diartikan sebagai manfaat atau balas jasa yang diterima oleh Pegawai Balai Kesehatan Olahraga Masyarakat dan Pelatihan Kesehatan Provinsi Sumatera Barat, baik berbentuk finansial maupun berbentuk non financial dengan enam butir pernyataan (Mondy, R.W., R.M. Noe dan S.R. Premeaux (1993).

\section{HASIL DAN PEMBAHASAN}

\section{Profil Responden}

Profil responden dibedakan atas lima kategori yaitu jenis kelamin, umur, pendidikan terakhir, jabatan, pangkat/golongan dan masa kerja. Berdasarkan proses tabulasi data terhadap 50 orang responden.

Berdasarkan hasil penelitian tentang karakteristik responden pertama jenis kelamin bahwa dari 50 orang responden, mayoritas mereka adalah perempuanyaitu sebanyak 30 orang $(60 \%)$, sementara sisanya laki-laki sebanyak 20 orang $(40 \%)$.

Karakteristik responden kedua adalah berdasarkan umur, dimana mayoritas responden adalah mereka yang berusia > 46 tahun sebanyak 19 orang (38\%), 41 - 45 tahun yaitu sebanyak 14orang (28\%),kemudian diikuti mereka yang berusia antara 31 - 35tahun sebanyak 11 orang $(22 \%)$ dan berusia lebih dari $<30$ tahun masing-masing sebanyak 3 orang $(6 \%)$.

Karakteristik responden ketiga adalah berdasarkan pendidikan terakhir, dimana mayoritas responden adalah mereka yang berpendidikan terakhir SMA yaitu sebanyak 29 orang $(58.0 \%)$, kemudian diikuti mereka yang berpendidikan Sarjana sebanyak 8 orang (16\%), pendidikan pascasarjan 7 orang (14\%) dan terakhir pendidikan Diploma III6 (12\%).

Karakteristik responden keempat adalah berdasarkan Pangkat/Golongan, dimana mayoritas responden adalah mereka dengan pangkat II/a - II/d sebanyak 23 orang (46\%), kemudian diikuti mereka dengan pangkat III/a - III/bsebanyak 12 orang $(24.0 \%)$, golongan IIIc -IIId sebanyak 12 orang (24\%) dan terakhir adalah mereka dengan pangkat IV/a - IV/bsebanyak3 orang $(6 \%)$.

Karakteristik responden kelima adalah berdasarkan masa kerja, dimana mayoritas responden adalah mereka yang telah bekerja17 orang (34\%), diikuti masa 
kerja $>21$ tahun sebanyak 14 orang (28\%). Sedangkan usia $6-10$ tahun dan $16-20$ tahun ,asing-masing sebanyak 9 orang atau sekitar masing-masing $18 \%$. Usia kerja terakhir berada pada usia $<5$ tahun sebanyak 1 orang $(2 \%)$.

\section{Uji Validitas dan Reliabilitas}

Menurut Sekaran (2003) suatu skala pengukuran dikatakan valid jika ia melakukan apa yang seharusnya dilakukan dan mengukur apa yang seharusnya diukur. Untuk mengetahui apakah instrument pertanyaan valid atau tidak valid, maka digunakan nilai Corrected Item-Total Correlation. Menurut Malhotra (1993) bila nilai Corrected Item-Total Correlation suatu butir pertanyaan berada diatas 0,30 maka butir pertanyaan tersebut dinyatakan valid, dan bila nilai Corrected Item-Total Correlation berada dibawah atau kurang dari 0.30, maka butir pertanyaan tersebut dinyatakan tidak valid. Dari hasil penelitian diperoleh sebagai terlihat pada table 1 dibawah ini:

Tabel 3

Hasil Uji Validitas Corrected Item-Total Correlation dan Cronbach's Alpha

\begin{tabular}{|l|c|c|c|c|c|c|}
\hline \multicolumn{1}{|c|}{ Variabel } & $\begin{array}{c}\text { Item } \\
\text { Pernyataan }\end{array}$ & $\begin{array}{c}\text { Batasan } \\
\text { Nilai } \\
\text { Valid }\end{array}$ & $\begin{array}{c}\text { Koefisien } \\
\text { Korelasi } \\
\text { (r) }\end{array}$ & $\begin{array}{c}\text { Keput } \\
\text { usan }\end{array}$ & $\begin{array}{c}\text { Cronb } \\
\text { ach's } \\
\text { Alpha }\end{array}$ & $\begin{array}{c}\text { Kepu } \\
\text { tusan }\end{array}$ \\
\hline Kinerja & $\begin{array}{c}\text { 1 s/d 6 } \\
\text { kecuali 5 }\end{array}$ & 0,300 & $\begin{array}{c}0,308- \\
0,505\end{array}$ & Valid & $\mathbf{0 , 6 7 9}$ & handal \\
\hline $\begin{array}{l}\text { Disiplin } \\
\text { Kerja }\end{array}$ & $\begin{array}{c}\text { 1 s/d 6 } \\
\text { kecuali 6 }\end{array}$ & 0,300 & $\begin{array}{c}0,496- \\
0,710\end{array}$ & Valid & $\mathbf{0 . 8 0 6}$ & handal \\
\hline $\begin{array}{l}\text { Kepuasan } \\
\text { Kerja }\end{array}$ & 1 s/d 5 & 0,300 & $\begin{array}{c}0,492- \\
0,828\end{array}$ & Valid & $\mathbf{0 , 8 6 7}$ & handal \\
\hline $\begin{array}{l}\text { Gaya } \\
\text { kepemimpin } \\
\text { an }\end{array}$ & 1 s/d 10 & 0,300 & $\begin{array}{c}0,668- \\
0,803\end{array}$ & Valid & $\mathbf{0 , 9 3 0}$ & handal \\
\hline
\end{tabular}

Sumber : Hasil Pengolahan Data Primer, 2015

Berdasarkan pada tabel 3 dapat dilihat bahwa ke enam butir pertanyaan yang digunakan untuk mengukur dimensi Kinerja dengan menggunakan Corrected ItemTotal Correlation adalah valid dengan nilai diatas 0,30 .

Besarnya nilai Cronbach's Alpha adalah 0.679, atau lebih besar dari 0.70, sehingga dapat diinterprestasikan bahwa variabel Kinerja adalah andal dan reliabel. Berdasarkan pada tabel tersebut dapat dilihat bahwa ke lima butir pertanyaan yang digunakan untuk mengukur dimensi Disiplin kerjadengan menggunakan Corrected Item-Total Correlationadalah valid. Besarnya nilai Cronbach's Alpha adalah 0.806, atau lebih besar dari 0.70, sehingga dapat diinterprestasikan bahwa variabel Disiplin kerja adalah andal dan reliabel.

Untuk mengukur Variabel Kepuasan Kerja adalah valid. Hal ini dikarenakan nilai Corrected Item-Total Correlation dari ke lima pertanyaan tersebut lebih besar dari 0.30. Besarnya nilai Cronbach's Alpha adalah 0.867, atau lebih besar dari 0.70, sehingga dapat diinterprestasikan bahwa Variabel Kepuasan Kerja adalah andal dan reliabel.

Sedangkan Variabel Gaya Kepemimpinan adalah valid. Hal ini dikarenakan nilai Corrected Item-Total Correlation dari ke sepuluh pertanyaan tersebut lebih besar dari 0.30. Besarnya nilai Cronbach's Alpha adalah 0,930 atau lebih besar dari 0.70 , sehingga dapat diinterprestasikan bahwa variabel Gaya Kepemimpinan adalah andal dan reliabel. 


\section{Distribusi Frekuensi Jawaban Responden}

Berdasarkan tabel 4 dapat dilihat bahwa bahwa nilai rata-rata variabel Kinerja adalah 4.32.Adapun pencapaian Persentase Skor Rata-Rata dari variabel adalah 86,40. Ini dapat dikatakan bahwa Kinerja di Balai Kesehatan Olahraga Masyarakat dan Pelatihan Kesehatan Provinsi Sumatera Barat termasuk dalam kategori cukup tinggi. dan tingkat capaian rata-rata (TCR) sebesar $82.0 \%$.

Dari lima butir pertanyaan yang digunakan dalam mengukur variabel Kinerja, nilai rata-rata tertinggi terletak pada butir ke satu dan ke dua yaitu "Saya mampu menyelesaikan pekerjaan yang diberikan dengan baik" dengan skor rata-rata 4.32. Hal ini berarti bahwapegawai di Balai Kesehatan Olahraga Masyarakat dan Pelatihan Kesehatan Provinsi Sumatera Barat selalu mempunyai kemauan keras dalam bekerja dan selalu ingin sibuk" dan Saya mampu memenuhi tanggung jawab seperti yang dijelaskan dalam uraian pekerjaan. Sedangkan nilai rata-rata terendah terletak pada butir ke tujuh belas yaitu "Sayamampu memenuhi standar mutu yang telah ditentukan oleh organisasiyaitu 4,10. Hal ini berarti bahwapara pegawai masih belum ingin terlibat secara total dalam pekerjaannya sehingga memenuhi standar mutu yang telah dietentukan, untuk Balai Kesehatan Olahraga Masyarakat dan Pelatihan Kesehatan Provinsi Sumatera Barat perlu meningkatkan keterlibatan para pegawai dalam pekerjaan.

Tabel 4 juga menggambarkan nilai rata-rata Variabel Kepuasan Kerja adalah 4.14.Adapun pencapaian persentase Skor Rata-Rata dari variabel Kepuasan Kerja adalah 82,72\%.. Hal ini dapat diartikan bahwa Kepuasan Kerja di Balai Kesehatan Olahraga Masyarakat dan Pelatihan Kesehatan Provinsi Sumatera Barat termasuk dalam kategori cukup tinggi. dan tingkat capaian rata-rata (TCR) sebesar $82,72 \%$. Dari lima butir pertanyaan yang digunakan dalam mengukur variabel Variabel disiplin Kerja, nilai rata-rata tertinggi terletak pada butir ke satu yaitu "Saya menghargai dan menghormati aturan yang berlaku" dengan skor rata-rata 4.30. Hal ini berarti bahwabagi pegawaiBalai Kesehatan Olahraga Masyarakat dan Pelatihan Kesehatan Provinsi Sumatera Barat mengikuti dan menghormati aturan berlaku. Sedangkan nilai rata-rata terendah terletak pada butir kelima yaitu "Saya selalu bekerja dengan semangat dan bergairah" dengan skor rata-rata sebesar 4,02. Hal ini berarti bahwa para pegawai selalu bekerja dengan semangat dan bergairah.

Berdasarkan pada tabel 4 dapat dilihat bahwa nilai rata-rata Variabel Kepuasan Kerja adalah 3,58. Adapun pencapaian Persentase Skor Rata-Rata dari variabel Kepuasan Kerja71,52\% Hal ini dapat diartikan bahwa kepuasan kerja di Balai Kesehatan Olahraga Masyarakat dan Pelatihan Kesehatan Provinsi Sumatera Barat termasuk dalam kategori kurang tinggi. dan tingkat capaian rata-rata (TCR) sebesar 71,52\%. Dari lima butir pertanyaan yang digunakan dalam mengukur variabel Variabel Kepuasan Kerja, nilai rata-rata tertinggi terletak pada butir ke satu yaitu "Saya puas dengan Pekerjaan saya secara keseluruhan" dengan skor rata-rata 4.12. Hal ini berarti bahwabagi pegawaiBalai Kesehatan Olahraga Masyarakat dan Pelatihan Kesehatan Provinsi Sumatera Barat merasa merasa puasa dengan pekerjaan secara keseluruhan Sedangkan nilai rata-rata terendah terletak pada butir kelima yaitu "Saya diberikan Kesempatan untuk maju dalam organisasi ini" dengan skor rata-rata sebesar 3.36. Hal ini berarti bahwa para pegawai masih diberikan Kesempatan untuk maju dalam organisasi ini.

Sedangkan bahwa nilai rata-rata variabel Gaya Kepemimpinan adalah

3.78.Adapun pencapaian Persentase Skor Rata-Rata dari variabel Gaya Kepemimpinan adalah sebesar 75,60\%. Hal ini dapat diartikan bahwa Gaya 
Kepemimpinan di Balai Kesehatan Olahraga Masyarakat dan Pelatihan Kesehatan Provinsi Sumatera Barat termasuk dalam kategori cukup tinggi. dan tingkat capaian rata-rata (TCR) sebesar $75,60 \%$. Dari delapan butir pertanyaan yang digunakan dalam mengukur variabel Gaya Kepemimpinan, nilai rata-rata tertinggi terletak pada butir ke tiga dan kedelapan yaitu "Sangat sulit menemukan seseorang yang dapat memimpin organisasi ini lebih baik daripada pemimpin yang ada sekarang" dan "Pemimpin memberi kesempatan para pengikut untuk mencapai sesuatu dengan cara mereka sendiri"dengan skor rata-rata masing-masing 3.94. Hal ini berarti bahwapegawai melihat pemimpin sangat sulit menemukan seseorang yang dapat memimpin organisasi ini lebih baik daripada pemimpin yang ada sekarang serta pemimpin memberi kesempatan para pengikut untuk mencapai sesuatu dengan cara mereka sendiri. Sedangkan nilai rata-rata terendah terletak pada butir ke sepuluh yaitu "Pemimpin mampu memberikan contoh kepada bawahan" dengan skor rata-rata sebesar 3.52. Hal ini berarti bahwapegawai melihat pemimpin mereka mampu memberikan contoh kepada bawahan. Untuk lebih jelasnya terlihat pada table dibawah ini

Tabel 4

Hasil Uji Validitas Corrected Item-Total Correlation dan Cronbach's Alpha

\begin{tabular}{|l|c|c|c|}
\hline \multicolumn{1}{|c|}{ Variabel } & $\begin{array}{c}\text { Item } \\
\text { Pernyataan }\end{array}$ & Rerata & TCR (\%) \\
\hline Kinerja & 1 s/d 6 kecuali 5 & 4,32 & 86,40 \\
\hline Disiplin Kerja & $1 \mathrm{~s} / \mathrm{d} \mathrm{5}$ & 4,14 & 82,72 \\
\hline Kepuasan kerja & $1 \mathrm{~s} / \mathrm{d} 5$ & 3,58 & 71,52 \\
\hline Gaya Kepemimpinan & $1 \mathrm{~s} / \mathrm{d} 10$ & 3,78 & 75,60 \\
\hline
\end{tabular}

Sumber : Hasil Pengolahan Data Primer, 2015

\section{Uji Asumsi Klasik}

\section{Uji Linearitas}

Berdasarkan tabel 5 terlihat bahwa nilai signifikansi (Sig) dari masing-masing variabel bebas lebih besar dari tingkat signifikannya $(\alpha=0,05)$. Hal ini berarti variabel terjadi hubungan yang linear dari variabel bebas terhadap variabel terikat. Dengan demikian analisis regresi dapat dilakukan karena uji linearitas sudah memenuhi, seperti terlihat sebagai berikut:

Tabel 5

Hasil Uji Linearitas Variabel Penelitian

\begin{tabular}{|c|l|c|c|c|}
\hline No & \multicolumn{1}{|c|}{ Variabel } & Sig & Alpha & Keterangan \\
\hline 1 & Kinerja -Disiplin & 0,441 & 0,05 & Linear \\
\hline 2 & Kinerja- Kepuasan & 0,789 & 0,05 & Linear \\
\hline 3 & Kinerja - Kepemimpinan & 0,722 & 0,05 & Linear \\
\hline
\end{tabular}

Sumber : Hasil Pengolahan Data Primer, 2015

\section{Uji Normalitas}

Berdasarkan pengujian normalitas terhadap kempat variabel, Pada Tabel 6 hasil uji Kolmogrov Smirnov terlihat nilai signifikansi (Sig) semua variabel penelitian lebih besar dari tingkat signifikan yang digunakan pada penelitian ini $(\alpha=0,05)$. Dengan demikian dapat dikatakan bahwa semua variabel penelitian berdistribusi normal, berarti analisis regresi dapat dilaksanakan karena data telah berdistribusi normal. Oleh karena itu uji normalitas terpenuhi. 
Tabel 6

Hasil Uji Normalitas Data

\begin{tabular}{|c|l|c|c|c|}
\hline No & \multicolumn{1}{|c|}{ Variabel } & Sig & Alpha & Keterangan \\
\hline 1 & Kinerja & 0,171 & 0,05 & Normal \\
\hline 2 & Disiplin & 0,310 & 0,05 & Normal \\
\hline 3 & Kepuasan & 0,314 & 0,05 & Normal \\
\hline 4 & Kepemimpinan & 0,064 & 0,05 & Normal \\
\hline
\end{tabular}

Sumber : Hasil Pengolahan Data Primer, 2015

\section{Uji Multikolinearitas}

Dengan menggunakan uji VIF yang di jabarkan dalam matrik korelasi, maka akan dapat di lihat apakah terdapat korelasi sesama variabel bebas (multikolinearitas), jika terdapat korelasi sesama variabel bebas di keluarkan dari analisis regresi berganda. Berdasarkan hasil olahan data diketahui bahwa Berdasarkan hasil uji multikolonieritas yang disajikan pada Tabel 7 diatas didapatkannya nilai tolerence untuk semua variabel bebas berada diatas 0,10 . Begitu juga jika dilihat dari nilai VIF (variance inflation factor), tidak satupun dari variabel bebas memiliki nilai VIF diatas 10. Jadi dapat disimpulkan bahwa variabel bebas dalam penelitian ini dinyatakan bebas dari moltikolonieritas. ini dapat dilihat pada tabel 7 berikut:

Tabel 7

Hasil Uji Multikolinearitas

\begin{tabular}{|c|c|c|c|c|}
\hline \multirow[t]{2}{*}{ No } & \multirow{2}{*}{ Variabel } & \multicolumn{2}{|c|}{$\begin{array}{l}\text { Collinearity } \\
\text { Statistics }\end{array}$} & \multirow{2}{*}{ Keterangan } \\
\hline & & Tolerance & VIF & \\
\hline 1 & Disiplin Kerja & 0,644 & 1,552 & Tidak Ada Multikolinearitas \\
\hline 2 & Kepuasan Kerja & 0,338 & 2,956 & Tidak Ada Multikolinearitas \\
\hline 3 & Kepemimpinan & 0,405 & 2,467 & Tidak Ada Multikolinearitas \\
\hline
\end{tabular}

Sumber : Hasil Pengolahan Data Primer, 2015

\section{Uji Heteroskedastisitas}

Uji Heteroskedastisitas bertujuan menguji apakah dalam model regresi terjadi ketidaksamaan varian dari residual satu pengamatan ke pengamatan yang lain. Berdasarkan analisis data untuk uji heteroskedastisitas sebagaimana yang terlihat pada Tabel 8 di atas, terlihat bahwa nilai signifikan dari semua variabel adalah lebih besar dari tingkat signifikan yang digunakan $(\alpha=0,05)$. Jadi dapat disimpulkan bahwa data hasil penelitian tidak mengalami kasus heteroskedastisitas sehingga analisis regresi dapat dilaksanakan.

Tabel 8

Hasil Uji Heterosksedastisitas

\begin{tabular}{|c|l|c|c|c|}
\hline No & \multicolumn{1}{|c|}{ Variabel } & Notasi & Sig & Keterangan \\
\hline 1 & Disiplin & $\mathrm{X} 1$ & 0,146 & Tidak Ada Heteros \\
\hline 2 & Kepuasan & $\mathrm{X} 2$ & 0,200 & Tidak Ada Heteros \\
\hline 3 & Kepemimpinan & $\mathrm{M}$ & 0,736 & Tidak Ada Heteros \\
\hline
\end{tabular}

Sumber : Hasil Pengolahan Data Primer, 2015 


\section{Uji Hipotesis Penelitian}

Berdasarkan hasil analisis MRA pada tabel 9 dapat dijelaskan model MRA 3 dapat dilihat variabel X1M (interaksi antara kepuasan kerja dan gaya kepemimpinan) memiliki nilai signifikansi sebesar 0.022. Nilai tersebut lebih kecil dari $(\alpha) 0,05$. Dengan demikian dapat disimpulkan bahwa gaya kepemimpinan berperan sebagai variabel moderasi pada pengaruh kepuasan kerja terhadap kinerja.

Pada model 3 juga dapat dilihat variabel X2M (interaksi antara Disiplin kerja dan gaya kepemimpinan) memiliki nilai signifikansi sebesar 0.036. Nilai tersebut lebih kecil dari $(\alpha)$ 0,05. Dengan demikian dapat disimpulkan bahwa gaya kepemimpinan berperan sebagai variabel moderasi pada pengaruh Disiplin kerja terhadap kinerja.

Untuk mengetahui apakah variabel gaya kepemimpinan memperkuat atau memperlemah pengaruh kepuasan kerja dan Disiplin kerja terhadap Kinerja dapat Pada model 1 ditemukan nilai koefisien regresi variabel disiplin kerja (X1) adalah 0.177 , sedangkan nilai koefisien regresi variabel interaksi antara variabel Disiplin Kerja dan gaya kepemimpinan (X1M) pada model 3 adalah 0.024. sehingga dapat disimpulkan bahwa nilai koefisien regresi variabel interaksi X1M pada model 3 lebih kecil dari nilai koefisien regresi variabel X1 pada model 1. Dengan demikian dapat disimpulkan bahwa variabel gaya kepemimpinan tidak memperkuat pengaruh kepuasan kerja terhadap Kinerja.

Selanjutnya $\mathrm{R}^{2}$ Model 1 adalah sebesar 0.108 (atau 10,8\%), sedangkan $\mathrm{R}^{2}$ Model 3 adalah sebesar 0.314 (atau 31,4\%). Sehingga terjadi peningkatan $\mathrm{R}^{2}$ sebesar 0.206 (atau 20,6 \%). Sehingga dapat disimpulkan bahwa variable kepemimpinan sebagai variable moderasi memperkuat pengaruh variable kepuasan kerja terhadap Kinerja sebesar 20,6\%. dengan demikian $\mathrm{H} 4$ dan $\mathrm{H} 5$ diterima. Untuk lebih jelasnya terlihat pada table 9 berikut;

Tabel 9

Hasil Analisa Regresi Bertingkat dengan Kompetensi paramedis sebagai variable pemoderasi

\begin{tabular}{|c|c|c|c|c|c|c|c|}
\hline \multirow{2}{*}{$\begin{array}{l}\text { Variabel } \\
\text { Terikat }\end{array}$} & \multirow{2}{*}{$\begin{array}{l}\text { Konstanta, } \\
\text { Variabel Bebas } \\
\text { dan Moderasi }\end{array}$} & \multicolumn{6}{|c|}{ Koefisien Regresi dan Signifikansi } \\
\hline & & $\begin{array}{c}\text { Tahap } \\
1\end{array}$ & Sig. & $\begin{array}{c}\text { Tahap } \\
2\end{array}$ & Sig. & $\begin{array}{c}\text { Tahap } \\
3\end{array}$ & Sig. \\
\hline \multirow{8}{*}{$\begin{array}{l}\text { Kepuasan } \\
\text { Pasien } \\
\text { (Y) }\end{array}$} & Konstanta (a) & 22,177 & 0,000 & 21,956 & 0,000 & 31,907 & 0,000 \\
\hline & Disiplin Kerja & 0,177 & 0,036 & 0,049 & 0,018 & 0,755 & 0,004 \\
\hline & Kepuasan & 0,082 & 0,031 & 0,353 & 0,002 & 0,030 & 0,017 \\
\hline & Kepemimpinan & & & 0,184 & 0,000 & 0,194 & 0,049 \\
\hline & X1_M & & & & & 0,024 & 0,022 \\
\hline & X2_M & & & & & 0,008 & 0,036 \\
\hline & $\mathrm{R}$ & \multicolumn{2}{|c|}{0,329} & \multicolumn{2}{|c|}{0,522} & \multicolumn{2}{|c|}{0,560} \\
\hline & $\mathrm{R}^{2}$ & \multicolumn{2}{|c|}{0.108} & \multicolumn{2}{|c|}{0,272} & \multicolumn{2}{|c|}{0,314} \\
\hline
\end{tabular}

Sumber : Hasil Pengolahan Data Primer, 2015

\section{Pembahasan Hasil Penelitian}

Berdasarkan hasil uji hipotesis tentang pengaruh Kepuasan Kerja dan Disiplinterhadap Kinerja padaBalai Kesehatan Olahraga Masyarakat dan Pelatihan Kesehatan Provinsi Sumatera Barat, hasil penelitian ini menemukan variable Kepuasan Kerja berpengaruh positif dan signifikan terhadap Kinerja.

Adapun hasil uji hipotesis yang menemukan Disiplin berpengaruh signifikan terhadap Kinerja, hal ini berarti bahwa KinerjaBalai Kesehatan Olahraga Masyarakat dan Pelatihan Kesehatan Provinsi Sumatera Barat dipengaruhi oleh variable Disiplin, 
tetapi saat ini kondisi Disiplin pada Balai Kesehatan Olahraga Masyarakat dan Pelatihan Kesehatan Provinsi Sumatera Barat telah baik. Adapun upaya yang perlu dilakukan dalam meningkatkan Kinerja pada Balai Kesehatan Olahraga Masyarakat dan Pelatihan Kesehatan Provinsi Sumatera Barat adalah dengan menjaga kondisi Disiplin kerja yang ada sekarang dan terus berusaha meningkatkannya. Hasil penelitian ini konsisten dengan hasil penelitian empiris terdahulu yang dilakukan oleh Rachmat Yakin (2004) yang berjudul " Analisis Hubungan Antara Sistem Disiplin Terhadap Motivasi dan Kinerja Karyawan Bagian Produktivitas Produksi PT. Sariwangi A.E.A”. Penelitian tersebut menunjukkan bahwa Disiplin tidak mempunyai hubungan dengan Kinerja.

Berdasarkan hasil uji hipotesis tentang pengaruh Kepuasan Kerja dan Disiplinterhadap Kinerja padaBalai Kesehatan Olahraga Masyarakat dan Pelatihan Kesehatan Provinsi Sumatera Barat, hasil penelitian ini menemukan variable Kepuasan Kerja berpengaruh positif dan signifikan terhadap Kinerja, sedangkan variabel Disiplin tidak berpengaruh signifikan terhadap Kinerja. Koefisien regresi bertanda positif menunjukan terjadinya hubungan yang searah dari Kepuasan Kerja dan Disiplin terhadap Kinerja. Hal ini bermakna semakin baik implementasi Kepuasan Kerja pada Balai Kesehatan Olahraga Masyarakat dan Pelatihan Kesehatan Provinsi Sumatera Barat dimasa yang akan datang, maka akan semakin tinggi pula KinerjaBalai Kesehatan Olahraga Masyarakat dan Pelatihan Kesehatan Provinsi Sumatera Barat. Sebaliknya semakin buruk implementasi Kepuasan Kerja pada Balai Kesehatan Olahraga Masyarakat dan Pelatihan Kesehatan Provinsi Sumatera Barat dimasa yang akan datang, maka akan semakin rendah pula KinerjaBalai Kesehatan Olahraga Masyarakat dan Pelatihan Kesehatan Provinsi Sumatera Barat.

Hasil penelitian ini konsisten dengan hasil penelitian empiris terdahulu yang dilakukan oleh Said Musnadi Maulidar dan Mukhlis Yunus (2012) yang berjudul " Pengaruh Kepemimpinan Dan Kepuasan Kerja Terhadap Motivasi Kerja Dan Dampaknya Terhadap Kinerja Pegawai Dinas Perindustrian Perdagangan Koperasi Dan Usaha Kecil Menengah Aceh". Penelitian tersebut menemukan bahwa secara parsial variabel Kepuasan kerja berpengaruh positif terhadap Kinerja. Hasil penelitian ini juga konsisten dengan hasil penelitian empiris terdahulu yang dilakukan oleh Shandy Marsono (2012) yang berjudul " Pengaruh Kepemimpinan, Motivasi Dan Kepuasan Kerja Terhadap Kinerja Guru Smp Negeri II Jaten Kab. Karanganyar". Penelitian tersebut juga menemukan bahwa secara parsial variabel Kepuasan kerja berpengaruh positif terhadap Kinerja.

Berdasarkan hasil uji hipotesis tentang pengaruh Gaya Kepemimpinan terhadapKinerja padaBalai Kesehatan Olahraga Masyarakat dan Pelatihan Kesehatan Provinsi Sumatera Barat, hasil penelitian ini menemukan Gaya Kepemimpinan berpengaruh signifikan terhadap Kinerja. Koefisien regresi bertanda positif menunjukan terjadinya hubungan yang searah dari Gaya Kepemimpinan terhadap Kinerja. Hal ini bermakna semakin baik implementasi Gaya Kepemimpinan pada Balai Kesehatan Olahraga Masyarakat dan Pelatihan Kesehatan Provinsi Sumatera Barat dimasa yang akan datang, maka akan semakin tinggi pula KinerjaBalai Kesehatan Olahraga Masyarakat dan Pelatihan Kesehatan Provinsi Sumatera Barat. Sebaliknya semakin buruk implementasi Gaya Kepemimpinan pada Balai Kesehatan Olahraga Masyarakat dan Pelatihan Kesehatan Provinsi Sumatera Barat dimasa yang akan datang, maka akan semakin rendah pula KinerjaBalai Kesehatan Olahraga Masyarakat dan Pelatihan Kesehatan Provinsi Sumatera Barat.

Hasil penelitian ini konsisten dengan hasil penelitian empiris terdahulu yang dilakukan oleh Said Musnadi Maulidar dan Mukhlis Yunus (2012) yang berjudul " 
Pengaruh Kepemimpinan Dan Kepuasan Kerja Terhadap Motivasi Kerja Dan Dampaknya Terhadap Kinerja Pegawai Dinas Perindustrian Perdagangan Koperasi Dan Usaha Kecil Menengah Aceh". Penelitian tersebut menemukan bahwa ada hubungan yang signifikan antara variabel Gaya Kepemimpinanterhadap Kinerja karyawan. Hasil penelitian ini tidak konsisten dengan hasil penelitian empiris terdahulu yang dilakukan oleh Shandy Marsono (2012) yang berjudul " Pengaruh Kepemimpinan, Motivasi Dan Kepuasan Kerja Terhadap Kinerja Guru Smp Negeri II Jaten Kab. Karanganyar". Penelitian tersebut menemukan bahwa Kepemimpinan berpengaruh negative dan tidak signifikan terhadap Kinerja.

Berdasarkan hasil analisis MRA yang digunakan untuk mengetahui pengaruh variabel gaya kepemimpinan (M) sebagai variabel moderasi pada hubungan antara variabel kepuasan kerja (X1) dan Disiplin (X2) terhadap Kinerja (Y), ditemukan pada model MRA 3 dapat dilihat variabel X1M (interaksi antara Disiplin kerja dan gaya kepemimpinan) memiliki nilai signifikansi sebesar 0.024. Nilai tersebut lebih besar dari $(\alpha)$ 0,05. Dengan demikian dapat disimpulkan bahwa gaya kepemimpinan berperan sebagai variabel moderasi pada pengaruh Disiplin kerja terhadap Kinerja.

Berdasarkan hasil analisis MRA yang digunakan untuk mengetahui pengaruh variabel gaya kepemimpinan (M) sebagai variabel moderasi pada hubungan antara variabel disiplin kerja (X1) dan Kepuasan Kerja (X2) terhadap Kinerja (Y), ditemukan pada model MRA 3 dapat dilihat variabel X2M (interaksi antara kepuasan kerja dan gaya kepemimpinan) memiliki nilai signifikansi lebih kecil dari $(\alpha) 0,05$. Dengan demikian dapat disimpulkan bahwa gaya kepemimpinan berperan sebagai variabel moderasi pada pengaruh Disiplin kerja terhadap Kinerja. Disamping itu Pada model 1 ditemukan nilai koefisien regresi variabel Kepasankerja (X2) adalah 0.082, sedangkan nilai koefisien regresi variabel interaksi antara variabel kepuasan kerja dan gaya kepemimpinan $(\mathrm{X} 2 \mathrm{M})$ pada model 3 adalah 0.008. sehingga dapat disimpulkan bahwa nilai koefisien regresi variabel interaksi X2M pada model 3 lebih kecil dari nilai koefisien regresi variabel X1 pada model 1. Dengan demikian dapat disimpulkan bahwa variabel gaya kepemimpinan memperkuat pengaruh kepuasan kerja terhadap Kinerja.

\section{E. PENUTUP}

\section{Kesimpulan}

Berdasarkan analisa data dan interpretasi yang telah disampaikan pada bab sebelumnya, maka dapat dikemukakan beberapa kesimpulan dari hasil penelitian ini sebagai berikut:

1. Kepuasan kerja berpengaruh signifikan terhadap Kinerja pegawai Badan Kesehatan Olahraga Masyarakat dan Pelatihan Kesehatan Provinsi Sumatera Barat.

2. Disiplin berpengaruh signifikan terhadap Kinerja pada Badan Kesehatan Olahraga Masyarakat dan Pelatihan Kesehatan Provinsi Sumatera Barat..

3. Gaya kepemimpinan berpengaruh signifikan terhadap Kinerja pegawai Badan Kesehatan Olahraga Masyarakat dan Pelatihan Kesehatan Provinsi Sumatera Barat.

4. Gaya kepemimpinan memperkuat pengaruh kepuasan kerja terhadap Kinerja pegawai Badan Kesehatan Olahraga Masyarakat dan Pelatihan Kesehatan Provinsi Sumatera Barat.. 
5. Gaya kepemimpinan memperkuat pengaruh Disiplin terhadap Kinerja pegawai Badan Kesehatan Olahraga Masyarakat dan Pelatihan Kesehatan Provinsi Sumatera Barat.

\section{Saran}

Hasil penelitian ini diharapkan akan memberikan bermanfaat pada pihak Pengambil kebijakan yaitu Pimpinan Badan Kesehatan Olahraga Masyarakat dan Pelatihan Kesehatan Provinsi Sumatera Barat. Saran praktis berdasarkan dari hasil penelitian ini adalah sebagai berikut:

1. Untuk meningkatkan Kinerja di Kantor Badan Kesehatan Olahraga Masyarakat dan Pelatihan Kesehatan Provinsi Sumatera Barat dimasa yang akan datang, maka perlu diperhatikan Gaya Kepemimpinan. Hal ini disebabkan karena Gaya Kepemimpinan berpengaruh signifikan terhadap Kinerja di Badan Kesehatan Olahraga Masyarakat dan Pelatihan Kesehatan Provinsi Sumatera Barat.

2. Untuk meningkatkan Gaya Kepemimpinan, maka Badan Kesehatan Olahraga Masyarakat dan Pelatihan Kesehatan Provinsi Sumatera Barat perlu meningkatkan implementasiKepuasan Kerja. Hal ini disebabkan Kepuasan Kerja berpengaruh secara signifikan baik terhadap Gaya Kepemimpinan maupun terhadap Kinerja di Badan Kesehatan Olahraga Masyarakat dan Pelatihan Kesehatan Provinsi Sumatera Barat.

3. Dalam upaya meningkatkan implementasi Kepuasan KerjaBadan Kesehatan Olahraga Masyarakat dan Pelatihan Kesehatan Provinsi Sumatera Barat, hendaknya dengan memberikan prioritas kepada :

a. Atasan memberikan kepercayaan kepada pegawai untuk mengerjakan pekerjaan yang tidak diberikan kepada pegawai lain.

b. Atasan memberikan kepercayaan kepada pegawai jika pegawai dapat menyelesaikan pekerjaan sesuai target yang ditetapkan.

c. Atasan memberikan kepercayaan kepada pegawai bekerja dengan kemampuan yang saya miliki.

d. Pegawai untuk mengerjakan pekerjaan yang menantang kemampuan mereka.

\section{Implikasi Penelitian}

Berdasarkan hasil uji hipotesis tentang pengaruh Kepuasan Kerja dan Disiplinterhadap Kinerja padaBalai Kesehatan Olahraga Masyarakat dan Pelatihan Kesehatan Provinsi Sumatera Barat, Maka Implikasi dari penelitian ini adalah untuk meningkatkan Kinerja perlu peningkatan pada variabel Kepuasan Kerja, dengan cara meningkatkan item butir pertanyaan yang dibawah rata-rata variabel.

Adapun hasil uji hipotesis yang menemukan Disiplin tidak berpengaruh signifikan terhadap variabel Kinerja (Y) adalah hal ini bukan berarti bahwa variabel Kinerja (Y) pada Balai Kesehatan Olahraga Masyarakat dan Pelatihan Kesehatan Provinsi Sumatera Barat tidak dipengaruhi oleh variable Disiplin, tetapi saat ini kondisi Disiplinpada Balai Kesehatan Olahraga Masyarakat dan Pelatihan Kesehatan Provinsi Sumatera Barat telah baik. Adapun upaya yang perlu dilakukan dalam meningkatkan Kinerja (Y) pada Balai Kesehatan Olahraga Masyarakat dan Pelatihan Kesehatan Provinsi Sumatera Barat adalah dengan menjaga tingkat Disiplin yang ada sekarang dan terus berusaha meningkatkannya. 


\section{DAFTAR PUSTAKA}

Agustia, D. (2011). Pengaruh locus of control dan perilaku kepemimpinan terhadap prestasi kerja dengan kepuasan kerja sebagai variabel intervening. Jurnal Ekuitas. 15 (1), 1-22.

Allen, N.J. \&Meyer, I.P. (1990). The measurement and antecedents of affektive, continuance, and normative commitment to the organization. Journal of Occupational Psychology, 91, 1-88.

Babakus, E. Cravens, D.W. Johnston, M. \&Moncrief, W.C.(2006). Examining the role of organizational variables in the salesperson job satisfaction model. Journal of Person Selling \& Sales Management, 16 (3). 100-116.

Bass.(1990).Menyatakan bahwa kualitas dari pemimpin sering kali dianggap sebagai faktor terpenting yang menentukan keberhasilan atau kegagalan organisasi.

Blakely, GL. (2003). The Effect of performance rating discrepancies on supervisors and subordinates. Organizational Behavior and Human Desicion Process. 54(1), 57-80.

Brown, U.J. \& Gaylor, K.P. (2002). Organizational commitment in higher education. Working Paper School of Business, Departement of Management and Marketing. Jackson State University.

Brunetto. Y., \& Wharton , F. (2002). The impact of supervisor communication on the job satisfaction of early career police officers IFSAM 2002. Conference Gold Coast. Queensland.

Buchanan, B. (2004). Building organizational commitment: The socialization of mangers in work organizations. Administrative Science Quarterly , 19, 533546.

Chong, V.K., \& Eggleton, I.R.C. (2003) The decision facilitating role of management accounting system on management performance: The influance of locus of control and task uncertainty. Advances in Accounting, 20, 165-197.

David Keith .(1985).Kepemimpinan adalah kemampuan untuk mempengaruhi orang lain untuk mencapai tujuan dengan antusias.

Deslanfy , S. (2005). Effect of leadership style on organizational commitment in PT Pos II Conesia (Persero) Semarang. Management \& Organization Studies Journals, 2(1), 69-84.

Dongoran, J. (2001). Komitmen Organisasi: Dua sisi sebuah koin. Dian Ekonomi, 7(1). 35-36.

Dwayne. G.M. (1997). Leadership practices and organizational commitment. Doktoral Disertation, Nova Southeastern University, unpublished. 
Eisenberg, E.M., Miller, K.I \& Monge, P.R. (2003). Involvement in communication networks as a preditor of organizational commitment. Human Communication Research, 10 (2). 179-201.

Feinstein, A.H. \& Vondrasek, D. (2001). A study of relationships between job satisfaction and organizational commitment among restaurant employees. Journal of Hospitality, Tourism and Leisure Science, 32, 1-12.

Ferdinand, A . (2002). Structural equation modeling dalam penelitian menajemen: Aplikasi model-model rumit dalam penelitian untuk tesis magister dan disertasi doctor ( $2^{\text {nd }}$ ed.). Semarang: FE Universitas Diponegoro Semarang.

Fletcher, M. (1999). The effect of internal communication, leadership and team performance on successful service quality implementasion a South African perspective. Team Performance Management Bradford, 5(5), 150-160.

Gaetner, K.N. \& Nollen, S.D. (2009). Career experiences, perceptions of employment practices and psychologycal commitment the organization. Human Relations, 42(11), 975-991.

Gary Yukl.(1994).Pemimpin yang efektif sanggup mempengaruhi para pengikutnya untuk mempunyai optimisme yang lebih besar, rasa percaya diri, serta disiplin kepada tujuan dan misi organisas.

Gray, J., \& Laidlaw, H. (2004). Improving the measurement of communication satisfaction, Management Communicational Quarterly, 17(3), 425-448.

Haryanto, B. (2008). Pengaruh budaya organisasi dan kepuasan kerja terhadap komitmen organisasi di kalangan Pegawai Universitas Muhammadiyah Sidoarjo. Jurnal Emisi, 1(1), 61-76.

Hughes, R.L., Ginnett, R.C., \& Curphy G.J. (2002). Leadership: Enhancing the lesson of experiance. New Jersey: Prentice-Hall.

Huselid, M.A. \& Day, N.E. (1991). Organization commitment, job involvement, and turnover: A subtantive and methodological analysis. Journal of Apllied Psycology, 76(3), 112-117.

Jablin, F.M. (2009). Superior-subordinate communication. the state of theory and research. Psychological Bulletin, 81(12), 1096-1112.

Katz, R. \& Thusman, M.L. (2003). A longitudinal study of the effects of boundary spanning supervision on turnover and promotion in research and development. Academy of Management Journal. 26(3). 437-456.

Katz \& Khan.(1978).Kepemimpinan yang efektif bisa membantu organisasi untuk bisa bertahan dalam situasi ketidakpastian dimasa datang. 
King, M., Murray, M.A., \& T. Atkinson. (2002). Background, personality, job characteristics and satisfaction with work in a national sample. Human Relations, 35(2), 119-133.

Koemono, H.T. (2007) Pengaruh kepimimpinan dan tuntutan tugas terhadap komitmen organisasi dengan variabel moderasi motivasi perawat rumah sakit swasta Surabaya. Jurnal Manajemen dan Kewirausahaan, 9(1), 30-40.

Lawler, E.E. \& Porter, L.W. (2006). Predicting managers pay and their satisfaction with their pay. Personnel Psychology, 19, 363-373.

Locke, E.A. (2003). Satisfiers and dissatisfiers among white-collar and blue-collar employees. Journal of Applied Psychology, 58, 67-76.

Lopopolo, R.B. (2002). The relationship of role-related variables to job satisfaction and commitment to the organization in restructured hospitas environment. Physical Therapy, 82(10), 1-15.

Nahavandi \& malekzadeh (1993 - 1987).Serta Kouzes \& Posner (1987) menyatakan bahwa pimpinan mempunyai pengaruh besar terhadap keberhasilan

Majorsy, U. (2007). Kepuasan Kerja, Kinerja dan komitmen organisasional pada staf pengajar Universitas Gunadarma. Jurnal Psikologi. 1(1), 63-72.

Malayu S.P.Hasibuan .(2005).Mengemukakan bahwa disiplin yang baik mencerminkan besarnya rasa tanggung jawab seseorang terhadap tugas-tugas yang diberikan kepadanya.

Mowday, R., Porter, L., \& Steers, R. (1982). Employee organization linkages. In P. Warr (Ed.), Organizational and occupational psychology. New York: Academic Press, 219-229.

Muchiri, K.M. (2002). The efeects of leadership style on organizational citixenhip behavior and commitment. Gadjah Mada International Journal of Busniess, 4(22), 265-293.

Yudistira, D. S., \& Susanti, F. (2019). Pengaruh Motivasi Kerja Dan Budaya Kerja Terhadap Kinerja Karyawan Dinas Pemberdayaan Masyarakat Dan Desa, Pengendalian Penduduk Dan Keluarga Berencana Kabupaten Pesisir Selatan. https://doi.org/10.31227/osf.io/jk54m

Ridho, M., \& Susanti, F. (2019). Pengaruh Stres Kerja Dan Motivasi Kerja Terhadap Kepuasan Kerja Pada Karyawan Bank Mandiri Syariah Cabang Padang. https://doi.org/10.31227/osf.io/pa2cg

Lubis, A. Y. O., \& Susanti, F. (2019). Pengaruh Gaya Kepemimpinan Dan Kompensasi Terhadap Prestasi Kerja Karyawan (Studi pada PT Japfa Comfeed Indonesia (JCI) Tbk Devisi Fam 1. https://doi.org/10.31227/osf.io/7tbrg 
Aldi, Y., \& Susanti, F. (2019). Pengaruh Stress Kerja Dan Motivasi Kerja Terhadap Prestasi Kerja Karyawan Pada PT. Frisian Flag Indonesia Wilayah Padang. https://doi.org/10.31227/osf.io/et4rn

Widodo, B. H., \& Susanti, F. (2019). Pengaruh Human Relation (Hubungan Antar Manusia), Lingkungan kerja Terhadap Etos Kerja karyawan (Studi Kasus Pada PT. Pelindo Teluk Bayur Padang ). https://doi.org/10.31227/osf.io/dxm8a

Junaidi, R., \& Susanti, F. (2019). Pengaruh Gaya Kepemimpinan Dan Budaya Organisasi Terhadap Kinerja Pegawai Pada UPTD Baltekkomdik Dinas Pendidikan Provinsi Sumatera Barat. https://doi.org/10.31227/osf.io/bzq75

Selamat, S. Heryanto, H. (2019). Affecting Factors In Employee Performance Koto Baru Sub-District, Dharmasraya District. Archives of Business Research 7 (7), 142-154

Ermayenti, E. Heryanto, H. (2019). The Effect Of Competence And Discipline Of Work On Public Satisfaction In The Regional Office Of The Ministry Of Religion In West Sumatera Province With Quality Of Service As An Intervening Variable. Archives of Business Research 7 (7), 69-87

Kurniawan, H. Heryanto, H. (2019). Effect of Work Discipline and Work Environment on Employee Performance with Work Motivation as an Intervening Variable in Department of Tourism, Youth and Sport of Padang District. Archives of Business Research 7 (7), 88-101

Sari, N. Heryanto, H. (2019). The Effect Of Training And Utilization Of SIPKD On Competency And Its Impact On The Quality Of Financial Statements In Dharmasraya Regency SKPD. Archives of Business Research 7 (7), $112-121$

Fatra, A. Heryanto, A. (2019). The Effect Of Implementation Of Population Administration Policy And Employee Motivation On Quality Of Service And Its Impact On Community Satisfaction In Issuance Of Birth ACCESS (Case in: The Department of Population and Civil Registration of the Dharmasraya Regency). Archives of Business Research 7 (7), 155-165

Yusrisal, Y. Heryanto, H.( 2019). The Influence of Leadership and Competence on Work Motivation and its impact on Employee Performance at the Koto Besar Sub-District Office, Dharmasraya Regency. Archives of Business Research 7 (7), 122-131

Syukri, M. Heryanto, H. (2019). The Influence Of Leadership Style, And Organizational Commitment, On Employee Discipline And Also Its 
Impact On Employee Performance Of The Dharmasraya District Community And Village Empowerment Office. Archives of Business Research 7 (7), 102-111

Septria, D. Heryanto, H. (2019). Performance Capability Analysis and Regional Budget Evaluation in Implementing Regional Autonomy in Dharmasraya District. Archives of Business Research 7 (7), 180-187

Meldi, M. Heryanto, H. (2019). The Influence Of Quality Of Human Resources And Communication On The Performance Of Civil Servants In The Regional Secretariat Of Dharmasraya Regency With Organizational Commitment As Intervening Variables. Archives of Business Research 7 (7), 132-141

Wahyuni, N. Heryanto, H. (2019). The Effect of Environment and Motivation on Employee Performance with Organizational Culture as an intervening variable on Bank Perkreditan Rakyat Jorong Kampung Tangah Pariaman PT. Archives of Business Research 7 (5)

Khamri, A. Heryanto, H. (2019). The Influence of the Work Environment, Work Discipline on the Spirit of Work and Its Impact on Employee Performance at the Dharmasraya District Health Office. Archives of Business Research $7(5)$

Irvan, RM. Heryanto, H. (2019). The Effect of Competence and Workload on Motivation and Its Impact on the Performance of Civil Servants at the Regional Secretariat of the Regency of Dharmasraya. Archives of Business Research 7 (5)

Jamilus, J. Heryanto, H. (2019). The Effect of Competence, Communication \& Motivation on Employee Performance in People's Welfare Regional Secretariat of Padang City, Indonesia. Archives of Business Research 7 (5)

Zukriah, A. Heryanto, H. (2019). The Effect Of Work Motivation And Discipline On Employee Performance In Human Resources Development Agency, West Sumatera With Education And Training As Variable Intervening. Archives of Business Research 7 (5)

Marunduri, P. Heryanto, H. (2019). Analysis of the Effect of Training and Motivation on Organizational Commitments and Its Impact on Employee Performance (Study on Insurance Marketing Agents on Prudential Agency Pru-Aini Gunung Sitoli PT). Archives of Business

Syamsudirman, S. Yurmain, H. Heryanto, H. (2019). Compensation and Work Culture on Organizational Performance with in mediation by Work 
Satisfaction in Fire Department Service of Sungai Penuh City. Archives of Business Research 7 (2)

Heryanto, H. (2019). The Effect of Work Motivation and Work Environment on Performance With Satisfaction as Intervening Variables Education Personnel Rektorate Andalas University. Archives of Business Research 7 (2)

Heryanto, H. Sumarni, S. (2019). The Effect of Certification, Competence, and Motivation on Teachers Performance of Country Civil Apparatus in Sawahlunto City. Archives of Business Research 7 (1)

Eliza, Y. (2015). Pengaruh moralitas individu dan pengendalian internal terhadap kecenderungan kecurangan akuntansi (Studi Empiris Pada SKPD di Kota Padang). Jurnal Akuntansi (Media Riset Akuntansi \& Keuangan) 4 (1), 86100

Eliza, Y. (2015). Pengaruh Investasi, Angkatan Kerja dan Pengeluaran Pemerintah terhadap Pertumbuhan Ekonomi di Sumatera Barat. PEKBIS (Jurnal Pendidikan Ekonomi Dan Bisnis) 7 (3), 198-208

Eliza, Y. Adriani, E. Maryanti, S. (2019). The Analysis Return on Investment Education of Married Woman in Indonesia. KnE Social Sciences, 667688-667-688

Maryanti, S. Eliza, Y. Wiyati, R. Thamrin, M. (2018). The Growth of the Population: Labor Potential Mapping in Pekanbaru Indonesia. IOP Conference Series: Earth and Environmental Science 175 (1), 012092

Eliza, Y. (2015). Analisis Kepuasan Masyarakat Atas Kualitas Pelayanan Kantor Kecamatan Siberut Selatan Kabupaten Kepulauan Mentawai. Jurnal Pendidikan Ekonomi dan Bisnis 7 (1), 65-75

Yuharmain, H. Suryana, Y. Novianty, R, Joeliaty. (2016). An Impact Study Of Rural Credit Bank Existence Towards Micro And Small Businesses In Padang City. International Journal Of Scientific \& Technology Research 5 (7), $145-150$

Edasa, D. Putra, EE. (2015). Pengaruh Gaya Kepemimpinan, Lingkungan Kerja dan Motivasi Kerja Terhadap Kinerja Pegawai LPP-RRI Bukittinggi. Jurnal Riset Manajemen Bisnis dan Publik 3 (2)

Putra, EE. (2015). Keadilan Dalam Organisasi. Buletin Organisasi dan Aparatur

Putra, EE. (2015). Pentingnya ISO Bagi Lembaga Pendidikan Dan Latihan. Buletin Badan Diklat Prov. Sumatera Barat 
Putra, EE. (2015). Urgensi Pengembangan Potensi Aparatur Sipil Negara (ASN). Buletin Badan Diklat Prov. Sumatera Barat

Putra, EE. (2014). The Effect of Human Capital, Structural and Customer Capital to Performance of Small Medium Enterprises at West Sumatera Province. Business Administration at Jose Rizal University

Putra, RY. Marlius, D. (2019). Pengaruh Pendidikan, Pengalaman Kerja dan Etos Kerja Terhadap Kinerja Pegawai Di KPN Batur. Academic Conference For Management 2.

Marlius, D. RD Putra. (2018). Strategi Pengembangan Sulam Bayang. Jurnal Benefita: Ekonomi Pembangunan Manajemen Bisnis Dan Akuntansi. Volume 3. No. 2. Hal. 204-218. http://doi.org/10.22216/jbe.v3i2.3494

Mukhyi, M.A. \& Subarti, T. (2007). Hubungan antara kepuasan kerja dengan komitemen dalam lingkungan pendidikan di Kota Depok. Procceding PESAT (Psikologi, Ekonomi, Sastra dan Sipil). Universitas Gunadarma.

Nowack, K. (2004). Does leadership practices affect a psychologically healthy workplace?. Working Paper. Consulting Tools Inc.

Pinder, C.C (2004). Work motivation: Theory, issues and applications. Illinois: Scoff, Foresmen and Company.

Porter 1996, dalam sunarsih (2001) tantangan dalam mengembangkan strategi organisasi yang jelas terutama terletak pada organisasi di satu sisi dan tergantung pada kepemimpinan. 
Ramayah, T. \& Aizzat, M.N. (2003). Job satisfaction and organizational commitmen: Differential effects for men and women. Jurnal Manajemen dan Bisnis, 5(1), 75-90).

Richards, B., Terance. O.B., \& Akroyd. D. (2002). Predicting the organizational commitmentof marketing education and health occupations education teachers by work related rewards. Journal of Industrial Teacher Education, 32(1), 114 .

Reilly, B.J. \& DiAngelo, J.A. Jr. (2010). Communication: A cultural system of meaning and value. Human Relations. 43(2), 129-140.

Robbins, S.P. (1998). Organizational Behavior. Sixth Edition. New Jersey: Prentice Hall.

Robbins, S.P. (2001). Perilaku organisasi: Konsep, kontroversi, dan aplikasi. Jilid 1. Edisi Dealapan. Edisi Bahasa Indonesia. Jakarta: PT. Prenhallindo (PearsonAsia Education, Pte., Ltd.).

Ruvendi, R. (2005). Rewards and influence of leadership style of employee job satisfaction, great hall of the Bogor agricultural products industry. Journal of Binaniaga, 1(1), 17-76.

Scholl, R.W. (1981). Differentiating organization commitment from expectancy as a motivating force. Academy of Management Review, 6(4), 589-599.

Scholl, R.W. (2002). Human resource strategies: Commitment and control approaches to workforce management. Resived: April 3, 2003. University of Rhode Island.

Scholl, R.W. (2002). Motivational processes- expectancy theory. Resived: October 12, University of Rhode Island.

Seniati, L. (2006). Pengaruh masa kerja, trait kepribadian, kepuasan kerja dan iklim psikologi terhadap komitmen Pegawai pada Universitas Indonesia, Makara, Sosial Humaniora, 10(2), 88-97.

Sheldon, M.E. (2001). Investments and involvements as mechanism produsing commitment to the organization. Administrative Science Quarterly, 16, 143150 .

Sigband, N.B. (2004). What's happened to employee commitment? Personnel Journal, 2, 131-135.

Steers, R.A. (1995). Organization effectiveness: A behavior view (2 ${ }^{\text {nd }}$ ed.). Jakart: Penerbit Airlangga.

Sudiro, A. \& Sumanang, N.F.A. (2005). Influance of effective communication in the organization of employee satisfaction on section production (Case study at PT Tirta Investama Pandaan). Journal of Management, 3(3), 204-211. 
Sutanto, E.M. \&Setiawan, B. (2000). Role of effective leadership styles in efforts improve employee morale and excitement of working in Sidoarjo Sinar Mas General Store. Jurnal Manajemen dan Kewirausahaan, 2(2), 29-43.

Sudiro, A. \& Sumanang, N.F.A. (2005). Pengaruh komunikasi yang efektif dalam organisasi terhadap kepuasan kerja karyawan pada bagian produksi (Studi pada PT Tirta Investama Pandaan). Jurnal Manajemen, 5(2), 162-175.

Testa, M.R. (2001). Organizational commitment, job satisfaction, and effort in the service environment. Journal of Psychology, 135(3), 226-237.

Tulus Tu'u .(2004).Menyatakan bahwa disiplin kerja penting artinya bagi kinerja pegawai,karena dengan displin kerja akan berlangsung pelaksanaan tugas dengan tata tertib,teratur,bertanggung jawab,serta terhindar dari pelanggaran.

Utomo. (2002). Kepemimpinan dan pengaruhnya terhadap prilaku citizienship (OCB), kepuasan kerja, dan perilaku oraganisasional (penelitian empiris pada Kabupaten Kebumen), Jurnal Riset Ekonomi dan Manajemen, 2(2), 34-52).

Yousef, A.D. (2000). Organizational commitment: A mediator of the relationship of leadership behavior with job satisfaction and performance in a non western country. Journal of Managerial Psycology, 15(1), 6-20. 